\title{
Questes
}

\section{Éléments bibliographiques}

\section{(2) OpenEdition}

1 Journals

Édition électronique

URL : http://journals.openedition.org/questes/5599

DOI : 10.4000/questes.5599

ISSN : 2109-9472

Éditeur

Les Amis de Questes

Édition imprimée

Date de publication : 11 novembre 2019

Pagination : 135-136

ISSN : 2102-7188

Référence électronique

«Éléments bibliographiques », Questes [En ligne], 41 | 2019, mis en ligne le 11 décembre 2019, consulté le 23 janvier 2020. URL : http://journals.openedition.org/questes/5599; DOI : 10.4000/ questes.5599 


\section{Éléments bibliographiques}

BenVEniste, Émile, « La blasphémie et l'euphémie », Problèmes de linguistique générale, Paris Gallimard, coll. « Tel », t. 2, 1966, rééd. 1974, p. 254-257.

BOURDIEU, Pierre, «Le capital social. Notes provisoires », Actes de la recherche en sciences sociales, $\mathrm{n}^{\circ} 31$, Parsi, Éditions de Minuit, 1980, p. 2-3.

-, Ce que parler veut dire, Paris, Fayard, 1982.

Casagrande, Carla et Vecchio, Silvana, Les Péchés de la langue : discipline et éthique de la parole dans la culture médiévale, trad. Philippe BAILLET, Paris, Édition du Cerf, 1991.

CoBBy, Anne, " “Chains de pute coroie, fel et deputaire", Les injures dans les fabliaux », dans L'Étude des fabliaux d'après le Nouveau Recueil Complet des Fabliaux, dir. Olivier COLLET, Fanny MAILlET et Richard TRACHSLER, Paris, Classiques Garnier, 2014, p. 119-139.

CORMIER, Raymond, «Brutality and Violence in Medieval French Romance and its Consequences ", dans Violence in Medieval Courtly Literature, dir. Albrecht Classen, New York/Londres, Routledge, 2004, p. 67-82.

Delumeau, Jean, Injures et blasphèmes, Paris, Imago, coll. « Mentaliés », 1989.

FERLAMPIN-HACHET, « De quelques noms d'oiseaux : remarques sur les insultes dans Artus de Bretagne ", dans Aimer, hä̈r, menacer, flatter... en moyen français, dir. Juhani HäRMÄ et Elina SuOMELA-HÄrmÄ, Paris, Honoré Champion, coll. « Bibliothèque du XV siècle », p. 181-192.

FLYNN, Charles P., Insult and Society : patterns of comparative interaction, Port Washington/New York, Kennikat Press, 1972.

GAUVARD, Claude, «De grace especial. » Crime, État et société en France à la fin du Moyen Âge, Paris, Publications de la Sorbonne, 1991.

-, « La Fama, une parole fondatrice », Médiévales, n²4, 1993, p. 5-13.

GOMPERTZ, Stéphane, «L'injure, le code, l'exclusion », Exclus et systèmes d'exclusion dans la littérature et la civilisation médiévales, Aix-en-Provence, Presses universitaires de Provence, coll. « Senefiance », 1978, p. 385-399.

GONTHIER, Nicole, "Sanglant Coupaul! », "Orde Ribaude!». Les injures au Moyen Âge, Rennes, PUR, coll. « Histoire », 2007.

GUIRAUD, Pierre, Les gros mots, Paris, PUF, coll. « Que sais-je ?», 1991.

HoAREAu-Dodinau, Jacqueline, Dieu et le roi. La répression du blasphème et de l'injure au roi à la fin du Moyen Âge, Limoges, PULIM, 2002.

Huston, Nancy, Dire et interdire : éléments de jurologie, Paris, Payot \& Rivages, coll. « Petite Bibliothèque Payot », 2002.

Les Insultes en français : de la recherche fondamentale à ses applications (linguistique, littérature, histoire, droit), dir. Dominique LAGORGETTE, Chambéry, Université de Savoie, coll. « Langages », 2009.

L'Invective au Moyen Âge: France, Espagne, Italie : actes du colloque des 4-6 février 1993 organisé par l'URA 1036 (Paris IV), l'École normale supérieure de Fontenay-Saint-Cloud, 
le Centre de recherches sur l'Espagne médiévale (Paris III), dir. Eric BEAUMATIN et Michel GARCIA, Atalaya $\mathrm{n}^{\circ}$ 5, Paris, Presses de la Sorbonne Nouvelle, 1995.

Invectives et violences verbales dans le discours littéraire, dir. Marie-Hélène LAROCHELLE, Québec, Presses de l'Université Laval, 2007.

LARGUECHE, Evelyne, L'effet injure : de la pragmatique à la psychanalyse, Paris, PUF, 1983.

-, « Le juron, parole sans foi ni loi, ou : du serment à l'injure », dans Le Serment, t. II, Théories et devenir, dir. Raymond VERDIER, Paris, Éditions du CNRS, 1991, p. 235-244.

-, L'injure à fleur de peau, Paris, L'Harmattan, 1993.

- «L'injure comme objet anthropologique », Revue des mondes musulmans et de la Méditerranée, $\mathrm{n}^{\circ} 103-104,2004$, p. 29-56.

-, Espèce de... ! Les lois de l'effet injure, Chambéry, Université de Savoie, 2009.

LAGORGETTE Dominique « Termes d'adresse, acte perlocutoire et insultes : la violence verbale dans quelques textes des $\mathrm{XIV}^{\mathrm{e}}, \mathrm{XV}^{\mathrm{e}}$ et $\mathrm{XVI}^{\mathrm{e}}$ siècles », dans La violence dans le monde médiéval, Aix-en-Provence, Presses universitaires de Provence, coll. «Senefiance », 1994, p. 317-332.

-, « Les syntagmes nominaux d'insulte et de blasphème : analyse diachronique du discours marginalisé », Thélème. Revista Complutense de estudios franceses dir. Amalia RODRIGUEZSomOLINOS, Madrid, Université Complutense, 2003, p. 171-188.

-, «Termes d'adresse, insultes et notion de détachement en diachronie », Cahiers de praxématique, n40, Linguistique du détachement, dir. Franck NEVEU, 2003, p. 43-70.

-, «Termes d'adresse et insultes : discours sur l'autre ou sur moi ? », dans The French Language and Question of Identity, dir. W. AYRES-BENETT et M. C. JONES, Londres, MHRAI Legenda, 2007, p. 116-128.

LEVELEUX-TEIXEIRA, Corinne, La parole interdite. Le blasphème dans la France médiévale, $X I I I^{e}-X V I^{e}$ siècles : du péché au crime, Paris, De Boccard, 2001.

LiTTLE, Lester K., « Formules monastiques de malédiction au $\mathrm{IX}^{\mathrm{e}}$ et $\mathrm{X}^{\mathrm{e}}$ siècles », Revue Mabillon, vol. LVIII, 1975, p. 377-399.

MADERO, Marta, Manos violentas, palabras vedadas. La injuria en Castilla y León (siglos XIIIXIV), Madrid, Taurus, 1992.

MArrou, Henri-Irénée, « La diatribe chrétienne », dans Patristique et humanisme, Paris, Éditions du Seuil, 1976, p. 267-275.

PERRET, Delphine, « Termes d'adresse et injures », Cahiers de Lexicologie, vol. XII, n², 1968, p. 3-14.

La renommée, dir. Claude GAUVARD, Médiévales, n²4, 1993.

SCHEIDEGGER, Jean, " Gros mots, gros rires? Le comique sémiologique de quelques fabliaux scabreux », dans Le Rire au Moyen Âge dans la littérature et dans les arts, dir. Thérèse Bouche et Hélène ChARPENTIER, Bordeaux, Presses Universitaires de Bordeaux, 1990, p. 309-322.

Rouayrenc, Catherine, Les Gros Mots, Paris, PUF, coll. « Que sais-je ? », 1996.

Violences médiévales, dir. Léonard DAUPHANT, Questes, n¹4, 2008. 